\title{
Un intérprete huasteco de Serapio D. Lorenzana
}

\author{
An huastec interpreter \\ of Serapio D. Lorenzana
}

\author{
José Manuel A. Chávez Gómez \\ Dirección de Estudios Históricos \\ Instituto Nacional de Antropología e Historia. México, D.F.
}

\section{RESUMEN}

El artículo reedita un antiguo manual escrito de manera didáctica que fue impreso para los viajeros, comerciantes y funcionarios públicos que frecuentaban la región Huasteca en el México de fines del siglo XIX. En dicha cartilla se enseñaba la manera en que el viajante debía de abordar y relacionarse con los productores teenek para adquirir materia prima, bienes manufacturados, mercancía suntuaria o cobrarles el impuesto respectivo. La intención del artículo es la de poner a disposición de los estudiosos de la región huasteca este texto que contiene información etnohistórica, así como de historia económica muy valiosa para la zona en el final del siglo XIX. El trabajo se complementa con un inédito estudio de carácter etnográfico sobre la vida actual de los teenek para poder observar qué cambios y permanencias se han dado entre ellos.

Palabras clave: Teenek, Idioma, Huasteca, Comercio, Viajeros.

\section{SUMMARY}

This article introducing an old manual written in a didactic way which was printed for travelers, merchants and government employees in late nineteenth century Mexico in the Huasteca region. The little book shows the manner to talk and relate with Teenek producers to purchase it raw materials, goods, sumptuary merchandise or charge taxes. Therefore the intention of this paper is to make available to scholars material that focuses in the Huasteca region. The book contains ethnohistorical information as well as invaluable economic dates of the area in the twilight of XIXth century. The work was complemented by an ethnographic study to invite to take a first look at the daily life of the Teenek, to see later what changes and permanence have among them.

Key words: Teenek, Language, Huasteca, Commerce, Travelers.

\section{INTRODUCCIÓN}

La intención de volver a editar Un intérprete huasteco se debe a su contenido muy interesante, que ha sido citado en varías etnografías, y que desde su aparición en 1896 no se ha publicado de nuevo. Sólo algunas bibliotecas lo conservan en su acervo, y 
entre ellas se encuentra la Biblioteca Manuel Orozco y Berra de la Dirección de Estudios Históricos de donde tomamos la información. El motivo principal de la edición es dar a conocer un texto que es una fuente obligada para quienes estudian la cultura e historia teenek, así como para los epigrafistas y mayistas en general.

Igualmente se hace una breve descripción del área huasteca, de sus habitantes, sus asentamientos y vida cotidiana para introducir al lector en la cultura huasteca, y que tenga las herramientas básicas para comprenderla con base en el contexto etnográfico de los teenek que aquí se describe.

El texto nos refiere un aspecto cotidiano de las relaciones habidas entre mestizos y teenek desde las poblaciones de Huejutla, en Hidalgo, hasta Tantoyuca, en Veracruz. Parece un libro hecho para el comerciante mestizo que recorría los caminos de la Huasteca desde el estado de Hidalgo hasta el de Veracruz, pasando también por el de San Luis Potosí. Describe cómo se daba la convivencia del mestizo con los huastecos, leyéndose qué productos manufacturaban y vendían, así como los que obtenían; probablemente productos suntuarios como el tabaco, que se producía en la región de Veracruz y quizás también se importaba de la Habana, Cuba.

\section{ETIMOLOGÍA DE LA PALABRA TEENEK}

La lengua pertenece a la familia mayance y sus hablantes la denominan teenek. Según parece, la locución teenek proviene de la contracción de Tee' Inik, donde el tee' se refiere a un adverbio cuyo significado es "aquí,, mientras que Inik, describe a un sustantivo y en este caso se traduce como "hombre"; así la significación que tendría la expresión sería la de "los hombres de aquí. Otra acepción que tiene el nominal teenek se refiere a los individuos "que viven en el campo con su idioma ${ }^{1}$, sangre y comparten la idea de ser ellos mismos" (Larsen 1997: 26, 53). De allí proviene el nominativo de teenek cauintalab, cuya traducción es "palabra o lengua de los teenek"; asimismo, como grupo humano se designan teenek bitsou que sería "el pueblo teenek" (Ibid: 7).

Por otra parte dicho término se esgrime en oposición a lo siguientes sujetos (Ibid: 63):

- ejek, que refiere al "negro o mestizo".

- thac tsan, literalmente "culebras blancas", refiriéndose a los nahuas.

- uuch o "piojos", que son los otomíes.

Lo anterior nos muestra cómo los teenek tienen una identidad propia, que contraponen a otros individuos diferenciándose claramente de ellos, aunque a veces se autodenigren, sintiéndose inferiores al compararse con los mestizos y los nahuas (Ariel de Vidas 2003: 207-210).

\section{DESCRIPCIÓN GEOGRÁFICA DEL ÁREA}

Los teenek se asientan en la parte noreste de México, en una planicie costera que va desde el norte de Veracruz diseminándose hacia el oriente de San Luis Potosí (Gallardo 2004: 6). En el estado de Veracruz se hallan dos núcleos de población principales:

\footnotetext{
${ }^{1}$ Para más información sobre la lengua teenek véase Grosser Lerner (1991) y Ochoa Peralta (1984).
} 
a) Circundante al municipio de Tantoyuca.

b) En los municipios, cabeceras y rancherías o congregaciones en la sierra de Otontepec e Ixhuatlán de Madero.

El área teenek veracruzana se distribuye en los municipios de Tantoyuca, Tempoal, Tantima, y Chinampa de Gorostiza, conviviendo con mestizos en las cabeceras municipales. Mientras que en Tancoco se relacionan con localidades nahuas; en dicha población, así como en las de Chinampa, Chontla, Tantoyuca, Tempoal y Tantima los teenek rebasan el 50\%, mientras que en Cerro Azul y Naranjos son sólo una quinta parte de la población (Valle 2004: 6).

En contraste, la mayoría de los teenek de San Luis Potosí residen en la región de la Huasteca, hacia el oriente del estado, situados en la cuenca del río Pánuco; esta región se divide en 18 municipios de los cuales los teenek viven en once de ellos. Estos concentran 90\% de dicha población, siendo los más importantes Aquismón, Tanlajás, Ciudad Valles, Huehuetlán, Tancanhuitz, San Antonio, Tampamolón y San Vicente Tancuayalab. Asimismo, en las principales localidades coexisten con mestizos y nahuas que ocupan el sur de la región (Gallardo 2004: 6).

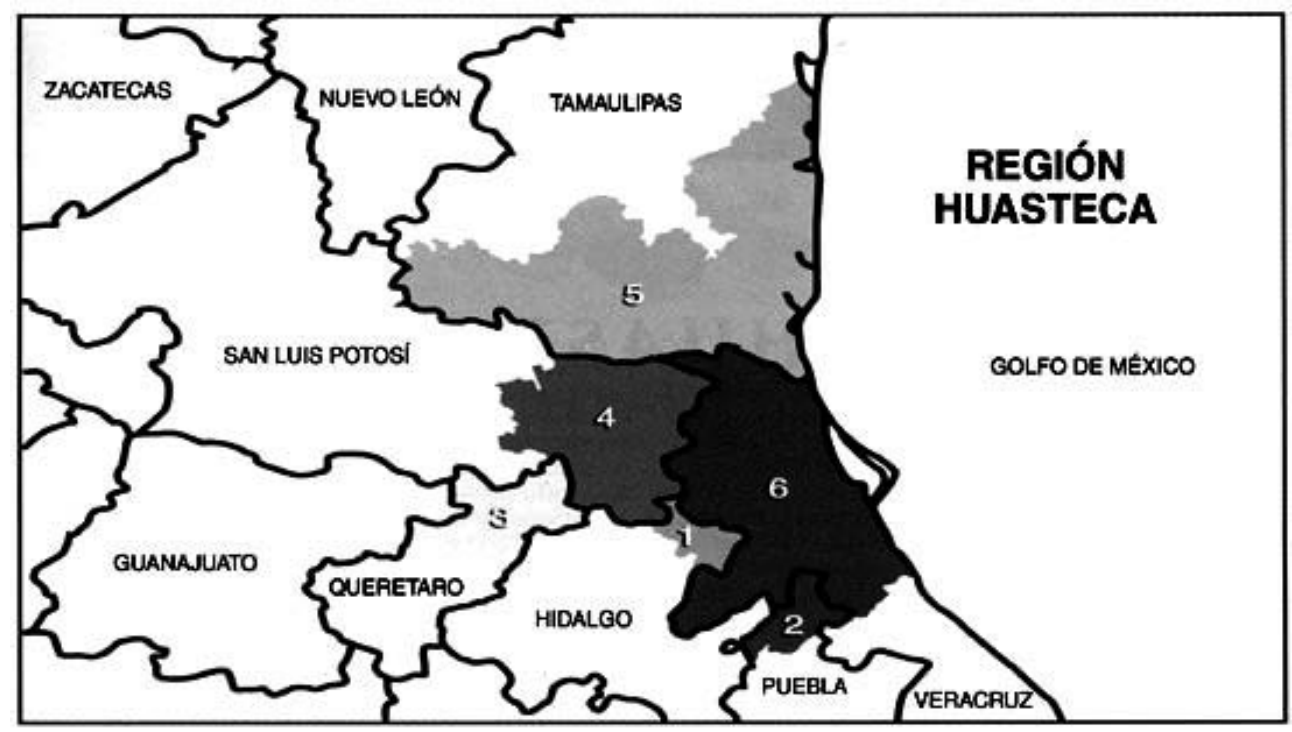

- HUASTECA DE HIDALGO

WUASTECA DE PUEBLA

S hUASTECA DE QUERETARo

an HUASTECA DE SAN LUIS POTOSI

E HUASTECA DE TAMAULIPAS

ED HUASTECA DE VERACRUZ

ESCALA 1:4,125,674

FUENTES: Dedimitación Administrativa de la Regionn Huasteca de la DGVC-CONACULTA; ITEA 2000, INEGI ELABOPADO: Departamento de Proyectos Y Contenidos Electrónicos de la DGCPL-CONACULTA 220404. 


\section{LA UNIDAD HABITACIONAL TEENEK}

La casa se encuentra en un terreno denominado solar que mide cerca de $25 \mathrm{~m}$. de largo por 20 de ancho. La construcción del hogar varía un poco en medidas y se han encontrado dos tipos de planta, cuadrangular y circular. La de planta cuadrada se caracteriza por tener una sola planta de siete metros de ancho por cuatro de ancho. Esta se subdivide en tres estancias, formando en la parte central un cuadrado de cuatro por cuatro metros y dos rectángulos laterales de metro y medio por tres metros (Ruvalcaba 1987: 7; Alcorn 1984: 113).

La casa tiene un recinto principal que cumple con varías funciones, como las de recibidor, sala, comedor y dormitorio, Mientras que los otros dos espacios son la cocina y otro dormitorio (Ruvalcaba 1987: 7). En la parte alta de la habitación bajo el techo, se levanta un entramado de varas que sirven de compartimentos usados como tapanco, troje, o bodega. En estas varas se amarran las hamacas y guardan las camas de tijera (Idem).

La habitación central también se usa como taller de trabajo, dependiendo de la época del año. Por ejemplo, cuando se realiza la cosecha de las milpas el maíz se va apilando en este espacio y luego lo suben al tapanco, colocándolo en hileras para que no se pudra y esté lejos de los animales. Más adelante se desgranará y usará para la comida o para la siguiente siembra (Alcorn 1984: 115).

Las camas usadas por los téenek están hechas de cedro o icte' (en su lengua). Se conforman con dos troncos que forman una cruceta cuyos extremos se ensamblan con travesaños de la misma madera y fijan con amarres de ixtle y un textil denominado zapupe o con costales. En esta parte descansa el cuerpo y se llega a cubrir con una colchoneta o sábana (Ruvalcaba 1987: 11-12). En esta zona de la vivienda hay un altar familiar colocado en una mesa donde están los santos venerados por la familia y los retratos de los familiares fallecidos. Cuando son las festividades de todos los santos en dicho altar se coloca la ofrenda a los muertos (Idem). En las paredes de la casa se cuelgan herramientas de trabajo, recipientes conteniendo alimentos, fotos y ropa. Todo pendido de diferentes clavos y sostenido por ganchos (Alcorn 1984: 127).

Con respecto al espacio destinado a la cocina, está conformado por un mampuesto hecho con piedras, ladrillo y arcilla aplanado. Sobre éste se distribuyen los cacharros, como ollas de barro, provenientes de Huejutla, ollas "chorreadas", cubetas de plástico o metálicas para acarrear el agua, un bote para cocer el nixtamal, una olla sólo para frijoles, otra para café, etc. En la pared o en el poste se cuelgan las cucharas, el soplador, la botella de petróleo, los hachones para el alumbrado, quinqués, etc. En dicho pretil hay una oquedad hecha para el fogón. En la parte alta cuelgan varios mecates para atar carne, tamales y bolsas conteniendo víveres, para evitar que los roedores, gatos y demás lleguen a ellos. Además, el humo del fogón permite conservar mayor tiempo los alimentos. El fogón por lo regular permanece encendido a lo largo del día, desde la cinco de la mañana para elaborar el desayuno, hasta las siete de la noche en que se prepara la cena. Mantener prendido el fuego obedece a la necesidad de elaborar tortillas en cada comida y al proceso de cocción del frijol, que requiere de mucho tiempo (Ruvalcaba 1987: 11-18).

El segundo tipo de vivienda teenek en realidad no dista mucho de la anterior, sólo que agrega otra construcción al conjunto habitacional. Es del mismo material y de 
una sola planta, pero carece de tapanco y la cocina se construye aparte; mide tres por cuatro metros. Los materiales usados en la edificación son distintos y los horcones son elaborados con chijol o habín [Piscidia communis (S.F. Blake) Harms]²; con una techumbre de palma y un envarillado de otate recubiertos con un aplanado de lodo. Dicha habitación tiene las funciones de sala-recibidor y dormitorio, en cambio, la cocina carece de enlucido y el varillado es más abierto para ventilar de mejor manera la habitación (Alcorn 1984: 116-117).

Este tipo de recinto se encuentra esquinado en el solar, en tanto que la cocina se localiza a un flanco. En ella se encuentra la mesa adosada al fogón, mientras que en el otro lado se distribuye un pretil construido para depositar las ollas, cubetas, jícaras o bules donde se guardan semillas y granos. Generalmente el resto del mobiliario se sitúa cerca de los postes y horcones principales de la estructura; en estos se clavan tablas de maderas que funcionan como repisas para alojar la vajilla de cuyas piezas sobresalen los platos, molcajetes, jarros y vasos. En las esquinas de la cocina se sitúan los bancos, bases trípodes y sillas que no se usan constantemente; lo mismo sucede con los útiles de limpieza, tales como escobas, recogedor, etc. (Ruvalcaba 1987: 13-14).

En las cocinas independientes se puede hallar un horno construido con ladrillo, emplazado sobre una plataforma, por lo regular ubicado a la mitad de la cocina, cuyas medidas oscilan alrededor de $1.20 \mathrm{~m}$ de largo, $0.60 \mathrm{~m}$ de alto. El horno es de base cuadrangular y la cúpula tiene una altura de 1.20 metros; el espesor de los muros es de 0.12 metros, con un enlucido interior hecho con barro, para mantener mejor el calor. Las familias que poseen uno de dichos hornos fundamentalmente lo usan para preparar pan, que venden con regularidad, excepto una mínima parte que es consumida por la familia u obsequiada a visitantes o familiares durante la celebración de la fiesta principal de la localidad (Ruvalcaba 1987: 14-15).

\section{ORGANIZACIÓN FAMILIAR}

La familia teenek se conforma de seis a siete miembros por cada núcleo familiar. En el mismo solar pueden vivir los abuelos, ya sea en pareja o sólo uno de ellos (Alcorn 1984: 127). Todos los adultos de la familia participan en el trabajo y mantenimiento del hogar, desde los ancianos, si aún pueden realizar las labores agrícolas, hasta los más jóvenes. Las niñas cuidan a los hermanos de menor edad, limpiando la casa y en la cocina, mientras que los niños acarrean agua, van por leña o acompañan a sus padres a la milpa. El padre y la madre son los encargados de disponer las labores en el hogar teenek, llevando a cabo las tareas más arduas en compañía de los hijos mayores (Ibid: 128).

El patrón de asentamiento de las casas teenek es muy parecido al de los mayas peninsulares, ya que en un terreno o solar se edifican las viviendas en la periferia

\footnotetext{
${ }^{2}$ En esta zona dicha especie se emplea en la construcción de casas con la elaboración de vigas, horcones, alfardas, tablas, pared, techo y cercado de la casa. También se usa en la producción de camas, mangos de herramientas, yugos, leña, puertas para ganado, y además como sombra para el ganado y postes para cercas (www.verarboles.com/Chijol/chijol.html).
} 
del terreno, mientras que las cocinas circundan el espacio interno, que sería el patio del solar. La ocupación del espacio teenek es patrilineal, cuando los hijos varones se casan construyen su casa en el solar, cercana a la de sus padres, y llevan a vivir allí a su esposa. Sin embargo, cada familia organiza sus ingresos y consumo de manera independiente, sólo cuando se solicita su ayuda atienden y participan en el trabajo recíproco, sobre todo con motivo de las festividades religiosas del pueblo, las familiares o las agrícolas particulares de siembra y cosecha en cada milpa (Ruvalcaba 1987: 23-24).

\section{ALIMENTACIÓN}

Cómo los demás grupos mayances, los teenek tienen al maíz en gran estima y lo usan en diferentes formas y guisos. En las comunidades de Tancoco y Xiloxúchitl hacen tres comidas al día (Ruvalcaba 1987: 17-19; Alcorn 1984: 127-128):

1.-El desayuno. Las mujeres son las encargadas de preparar el desayuno y se levantan a las cinco de la mañana a iniciar su faena en la cocina, para que en una hora ya esté preparada la mesa. El desayuno para los adultos se lleva a cabo a la seis, porque van a realizar sus labores en el campo, y los niños cerca de las ocho. Las porciones para adulto son exiguas y consisten en una taza de café negro, endulzada con panela o piloncillo y una pieza de pan; en ocasiones incorporan un puñado de galletas bizcocho (de animalitos). El café se ha vuelto un producto de primer orden en la dieta y consumo de los teenek; quizá introducido por los españoles y que poco a poco se fue arraigando en la región, sustituyendo las bebidas tradicionales hechas con maíz y cacao. Mientras tanto, el pan es elaborado de manera artesanal en hornos domésticos por una decena de familias que se dedican a tiempo completo a su elaboración, al menos tres veces a la semana (Idem).

2.-La comida. Cuando los hombres están en la milpa y las mujeres en las labores domésticas se hace un alto alrededor de las 11 del día para ingerir un pequeño almuerzo con tortillas, frijoles y salsas hechas con diversos chiles. A eso de la una de la tarde se lleva a cabo otra comida con mayor cantidad de alimentos y tortillas. Un almuerzo muy socorrido son las enchiladas, que se hacen con tortillas untadas con salsa picante, salsa de tomate o entomatadas y las enfrijoladas. Lo complementan con queso y algunas verduras, como calabaza, quelite, verdolaga, hongo, pipián, etc.; en muy raros casos con trocitos de carne. Para acompañar los alimentos los hombres que van a la milpa se llevaban su guaje, ahora sustituido por botellas de plástico de refresco comercial; si gusta del café lleva una porción. En un pedazo de plástico llevan sal y chile. Cabe resaltar que a las 11 de la mañana en las sementeras los hombres interrumpen su trabajo y van a cobijarse a la sombra de un árbol con follaje frondoso; en él debieron colgar su bastimento en bolsas que llevaban desde que salieron de su casa. Los hombres se sientan en corro y platican, se intercambian la sal o los chiles, y si abunda en su parcela, van por un poco de cilantro, cebollitas u otro vegetal que sirve de complemento a la comida. En la casa, las mujeres se sirven un plato con frijoles y una pila de tortillas recién hechas por ellas. Lo completan con un pequeño guisado con verduras, caldo de gallina, huevos o porciones de carne de animales domésticos o silvestres. También comen palmito, camote, yuca cocida y el 
plátano macho lo fríen, considerándolo un postre delicioso. El refresco embotellado es un ingrediente indispensable en la mesa de las viviendas teenek (Idem).

3.-La cena. Cuando los hombres regresan de la milpa y las mujeres terminan de asear y cocinar en el hogar, tiene lugar la hora del baño. Por lo regular a las seis de la tarde el hombre primero reposa para "enfriarse" del calor y del duro trabajo realizado; después se baña y, cerca de las ocho de la noche, la mujer ya tiene lista la mesa con alimentos. Estos casi son los mismos que se ingirieron al medio día con tortillas, frijoles, salsa, café y al hombre le dan un guisado con carne, verduras o sopa de pasta. Si es fecha festiva o época de maíz nuevo, se hacen tamales de elote y se sirven apilados en platos grandes para que los concurrentes los tomen. Las mujeres son las encargadas de hacer la cena entre las cuatro y cinco de la tarde; antes acarrean el agua, tanto para cocinar como para lavar ropa, lavar el nixtamal, lavar platos, el baño, etc. (Idem).

\section{LAS FIESTAS RELIGIOSAS Y EL CICLO AGRÍCOLA}

El santoral católico y el calendario agrícola de los teenek, como en toda Mesoamérica, muestran una aculturación y un paralelismo cultural muy interesante. Por un lado, la pervivencia de la antigua tradición prehispánica entremezclada con elementos católicos, produjeron una nueva cosmovisión teenek que subsiste hasta nuestros días. Está relación festiva y ritual con la vida cotidiana podía subdividirse en dos ámbitos: el religioso colectivo y el religioso privado. Las celebraciones religiosas son una mixtura entre la cosmovisión autóctona teenek con elementos del santoral católico español. En este rubro en San Luis Potosí se festeja a los santos patrones (Gallardo 2004: 9):

San José, el 19 de marzo;

San Isidro, el 15 de mayo;

Santiago Apóstol, el 25 de julio

San Agustín, el 28 de agosto

San Miguel, el 29 de septiembre

También se atienden otras fiestas del calendario católico como el Año Nuevo y el Día de Muertos. Estas fiestas se celebran religiosamente por la mañana, y la noche anterior con danzas y cohetes (Idem).

En Veracruz cambian los patronos de los pueblos (Ruvalcaba 1987: 47) celebrándose a:

San Isidro Labrador, el 15 de mayo

San Lucas, el 17 de septiembre

San Miguel, el 29 de septiembre

Virgen de la Concepción, el 8 de diciembre

Virgen de Guadalupe, el 12 de diciembre

La Semana Santa es muy importante porque marca el periodo de siembra de maíz y otros productos agrícolas; mientras que para los meses de octubre a diciembre se llevan a cabo la cosecha y almacenamiento de maíz y la plantación de las primeras mazorcas obtenidas en el anterior ciclo agrícola. La diferencia entre los santorales probablemente se relaciona con las diferentes órdenes misioneras que evangelizaron 
a los teenek en el periodo virreinal, destacándose los franciscanos y los agustinos en San Luis Potosí y Veracruz.

Los rituales privados en al ámbito doméstico por lo regular están vinculados al nacimiento de un vástago, al bautizo, el matrimonio, el cumpleaños de algún integrante de la familia y de un santo cuya devoción doméstica sea importante. Por último, el fallecimiento de un familiar también reúne a toda la parentela (Ibid:: 50).

En todas las celebraciones se reparte comida a los asistentes, sean tamales, adobos, pipianes, moles, café, galletas, aguardiente y cerveza. En las fiestas patronales y en los velorios se utilizan mucho las flores, velas y veladoras (Ibid: 51). Para el día de muertos, a los ausentes les preparan un tamal llamado en nahua zacahuilil o zacahuile ("tuza en canasta") que, junto con el mole y el pan, son alimentos ceremoniales imprescindibles que se depositan en los altares de las ofrendas. El componente primordial del zacahuile es el maíz, cuya masa debe ser martajada. Se adoba con chile seco, cascabel o chino. Los rellenos se componen de distintas carnes, de res, cerdo, pollo, pescado y/o mariscos, que se extienden en la masa en crudo. Después se envuelve con hojas de plátano o de papatla (platanillo) y se coloca en una batea de madera para que se guise. Luego se cuece en hornos de tierra, como los empleados para la barbacoa (calentados con leña), o en los de bóveda o barro como los de las panaderías. El tamal debe quedar perfectamente envuelto para que no se queme, y en su cubierta llegan a emplearse hasta 45 hojas, dependiendo de su tamaño; el cocimiento dura varias horas, porque se realiza a fuego lento (Martínez 2002: 89).

\section{LAS DANZAS}

Los teenek veracruzanos a la vez que festejan a sus santos patronos, transmiten su historia y su correlación con la naturaleza a través de la danza. Por ello existen diversos bailables como La danza de la Malinche, que representa la comprensión teenek de la Conquista; otros bailes son: de los Negros, del Gavilán, de la Rama de Navidad (Valle y Hernández 2006: 32). Entre las danzas teenek potosinas más importantes está el Tsacamson o danza pequeña. En ella los hombres se distribuyen en una hilera con listones de colores amarrados y colgando de la cabeza, con un espejo en la frente, mientras que las mujeres forman un círculo. Otro baile es el de Las Varitas, donde los varones bailan con cascabeles anudados en las piernas y varas amarradas con listones de colores; el de La Malinche, en el cual un individuo se disfraza de mujer; El Rey Colorado, en el que hombres y mujeres bailan formando dos circunferencias concéntricas que giran contrapuestas la una de la otra. Por último, La danza de El Volador, quizá la más conocida y famosa, en la que participan danzantes amarrados con cuerdas a la parte superior de un gran polín, que da vueltas en mientras los sujetos se balancean en el aire imitando el vuelo del gavilán hasta el llegar al suelo (Gallardo 2004: 34).

\section{COSMOVISIÓN}

La geografía sagrada de los teenek potosinos está delimitada por el camino diurno del sol; es decir, al este se encuentra el océano y al oeste la sierra. Las almas de 
la gente común descansan en la sección occidental, en tanto que los yerbateros, músicos y danzantes yacen en el oriente. Tanto por el movimiento heliacal, como por el rumbo de los vientos dominantes, que atraen a la lluvia, el este y el oeste son dos direcciones complementarias en el mundo de los teenek (Idem).

La esencia de la lluvia proviene del oriente y halla su contraparte en las cuevas del oeste. Cuando en el occidente cae una lluvia torrencial y el agua se lleva infinidad de cosas, estas aparecen en el este. Las grutas son numerosas en la serranía del oeste; en la cosmovisión teenek simbolizan las entradas al ámbito de las entidades divinas; son lugares de culto e intercambio ritual. En las cavidades submundanas mora el trueno, deidad todopoderosa dadora de la lluvia; asimismo se halla la diosa de la fertilidad (Gallardo 2004: 34; Alcorn 1984: 88). Para los teenek el lugar de su existencia es el monte o sierra; el mismo que se confronta al de los mestizos, que viven en el pueblo o ciudad. Por ello, los teenek tienen su vivienda más integrada en la naturaleza y sus productos. Por ende, la tierra es un lugar sagrado, sujeto de ceremonias, rituales y danzas, a la que se le brindan ofrendas durante el ciclo agrícola y los sepelios.

\section{EL MAÍZ, DEIDAD PRINCIPAL Y SÍNTESIS DE LA COSMOVISIÓN TEENEK}

En la Sierra de Otontepec, en el Estado de Veracruz, ciertas poblaciones teenek todavía realizan un inveterado ritual de petición denominado Dhipaak ${ }^{3}$. Este rito se inserta en el ciclo agrícola y su intencionalidad es solicitar la intervención de deidades relacionadas con la naturaleza, cuya presencia sea benéfica para la siembra, pero sobre todo para la cosecha. La ceremonia se practica en diferentes lugares, aunque la costumbre refiere su ejecución en las milpas y los cerros; sin embargo, en la actualidad se está llevando a cabo en las capillas de la localidad (Del Ángel Flores 2006). El Dhipaak es un ritual privado efectuado por una familia, en honor al espíritu sagrado del maíz Dhipaak, a la madre tierra y a Dios, con la finalidad de pedir una buena siembra y agradecer por anticipado una mejor cosecha de maíz. Dhipaak, es "el papá del maíz" o "espíritu del maíz", también en otras comunidades teenek se le conoce como "el dios de la fertilidad" y, a su vez, el término se traduce como maíz o mazorca. Entre los mismos indígenas se dice que todo teenek está hecho de maíz (Del Ángel Flores, 2006).

Desde enero hasta marzo, una vez que el periodo de siembra de cada hogar va concluyendo, el padre de familia o jefe de la casa convoca a cuatro niñas y un niño de entre seis y siete años, para cumplir con el Dhipaak. Las niñas usan un tocado en la cabeza con forma de corona hecha con la flor de Kaxiy wich, o flor de cempasúchil, y portan un cántaro de barro pintado de rojo con motivos florales (Alcorn 1984: 156; Del Ángel Flores 2006). En el altar familiar, junto del "Santito" que se ha dispuesto para la ocasión, se colocan de siete a catorce mazorcas, si se tienen dos variedades de maíz con los colores amarillo y morado. Estas son adornadas con collares de Kaxiy wich. Delante del altar se ubica una mesa en la cual las niñas toman el opíparo caldo de pollo y el atole, que las mujeres de la familia anfitriona prepararon para ellas.

\footnotetext{
${ }^{3}$ Para mayor detalle y estudio del tema véase Ochoa (2000).
} 
Mientras tanto, el niño primero sahuma el altar, después sigue con las mazorcas, la familia y termina con la comida. En tanto las niñas comen, el dueño de la casa les invita a un "topo de caña", que es aproximadamente $1 / 4$ litro de aguardiente; la primer muchacha finge tomar un trago y enseguida lo circula a las otras, que hacen lo mismo. El niño sí le da un sorbo al aguardiente de caña y lo expulsa rociando el altar. Una vez que las niñas finalizan de comer, el jefe de la familia o el dueño de la casa distribuye las mazorcas entre los infantes, tocándoles de dos o tres a cada niña y las restantes se dividen entre el niño y los familiares que atestiguaron el ritual. Todo esto se realiza como un acto de "compartir la suerte", si bien las chiquillas conservan los "collarcitos" que las adornaban (Idem).Y para concluir dicha acción ritual, toda la familia se encamina a la sementera para enterrar los huesos de pollo dejados por las niñas. De la misma manera, los collarcillos de flores que portaban los cuelgan de las matas secas de maíz que quedaron erguidas después de la pizca. A continuación, rocían por toda la milpa el topo de aguardiente que las niñas aparentaron beber (Del Ángel Flores 2006). Así, los teenek proveen de alimento a la tierra para retribuirle los productos que obsequia; además es una manera de fortalecer la abundancia y la gracia para las cosechas venideras.

\section{NOTAS BREVES SOBRE UN INTÉRPRETE HUASTECO}

El pequeño libro de Un intérprete buasteco tiene la forma de un manual para aprender de manera rápida lo esencial del idioma teenek; tanto por su organización, como por las categorías empleadas en los elementos idiomáticos, deja ver que al autor tenía un conocimiento detallado del área Huasteca.

Desafortunadamente no se han encontrado datos de la vida del autor del texto (Serapio D. Lorenzana), por lo que sigue siendo una incógnita qué cargo pudo tener en la administración pública o política de la época porfiriana.

Asimismo debemos destacar que el recopilador de las frases pudo conocer la lengua teenek desde su nacimiento o juventud, por la forma en que establece la estructura gramatical de la misma. El manejo de los pronombres personales, del objeto-verbosujeto parecen estar bien identificados. El autor estructuró su trabajo como si fuera una cartilla escolar básica, iniciando con la identificación personal y, como toda persona bien educada, agregó las salutaciones necesarias; además de iniciar un diálogo elemental con un indígena teenek. Pareciera que esbozó la manera en que podría acercarse a un teenek con las frases exactas para que este tuviera un poco de confianza con el interlocutor, ya que los huastecos solían mostrarse algo recelosos.

El autor parece dirigir su obra a un tipo de lector muy especial, que tuviera un nivel educativo y económico relativamente desahogado, porque en la sección de dinero y compra-venta destaca, por un lado, el tipo de productos que se vendían en la Huasteca a fines del siglo XIX, pero por otro, subraya cómo el aprendiz del idioma huasteco debe cobrar impuestos. Así, se puede deducir que el texto de Un intérprete buasteco estaba destinado a comerciantes y funcionarios públicos que cobraban las cargas tributarias gubernamentales y frecuentaban la región cabalgando desde Huejutla

\footnotetext{
${ }^{4}$ En el texto se da el nombre teenek para Huejutla que es Dac-tocóll.
} 
Hidalgo, pasando por San Luis Potosí hasta Tantoyuca, Veracruz. La importancia de las poblaciones citadas en el trabajo debió deberse a su producción de materias primas o bienes manufacturados.

Para finales del siglo XIX la Huasteca, de acuerdo al libro que aquí analizamos, producía café, tabaco, ixtle para cuerdas, mecates y lacería; sombreros, fibras para textiles como algodón para la zaraza ${ }^{5}$, dril ${ }^{6}$ y cerámica. Del mismo modo, parecía importar tabaco cubano; probablemente algunos hacendados tenían contacto con la isla de Cuba, que era un punto intermedio para obtener mercancías suntuarias e industriales provenientes de Europa y Estados Unidos. Es muy probable que los acaudalados de la Huasteca gustaran de fumarse un buen habano aunque, en su defecto un cigarro puro proveniente de Veracruz, también sería bien recibido.

Asimismo, la manufactura de zapatos pudo ser otro de los productos significativos de la región, porque en el manual se destaca la manera de encargar un buen calzado a un zapatero huasteco. De igual manera, se les solicitaba a los sastres locales que hicieran ropa de muy buena hechura. En la región el ganado y la caza parecen haber sido una fuente de obtención de alimento, piel y cuero para la talabartería y para la confección de ropa y zapatos.

Con base en lo anterior, se puede decir que el libro que aquí presentamos fue un manual para comerciantes de materias primas, tabaco, talabartería, ropa y lacería; así como para oficiales gubernamentales de la secretaría de Hacienda y finanzas del gobierno porfiriano. Todo esto indicaría que, al menos desde el siglo XIX, la Huasteca fue una región rica en producción y manufactura de bienes de consumo, que mantenía un intenso comercio regional y foráneo. Por ello este cuadernillo es muy importante para los investigadores que estudian la Huasteca, tanto en el ámbito histórico y antropológico, como en el lingüístico. Dejamos así este texto como un importante testimonio de lo que fue la Huasteca decimonónica prerrevolucionaria.

\footnotetext{
${ }^{5}$ Tela de algodón estampada (Diccionario de la Real Academia Española, 2010).

${ }^{6}$ Tela fuerte de hilo o de algodón crudo (Diccionario de la Real Academia Española, 2010).
} 
UN

INTÉRPRETE HUASTECO

AYUDA VALIOSA PARA

LOS QUE QUIERAN HABLAR ESTE IDIOMA

\section{FORMADO POR}

S E R A P I O. D. L O R E N Z A N A

Se publica por acuerdo de la Secretaría de Fomento.

MÉXICO

OFICINA TIP. DE LA SECRETARÍA DE FOMENTO

1896 


\section{UN INTÉRPRETE \\ OBRITA HUASTECA}

A la mano para comprar y vender en este territorio.

Las personas que desean aprender el idioma huaxteco, no necesitan otra cosa más que dedicarse al estudio de esta obrita; ofrezco seguras garantías de adelanto sin tropiezos y dificultades; creo que por medio de la presentación sistemática de frases y diálogos fáciles que formo, aprenderán pronto; pues este libro viene á ser un intérprete útil y siempre listo á indicar la frase que debe emplearse para expresar un deseo cualquiera.

E X P L I C A C I O N

El número que tiene cada frase castellana, lo tiene también cada huaxteca para evitar dificultades en leer. 


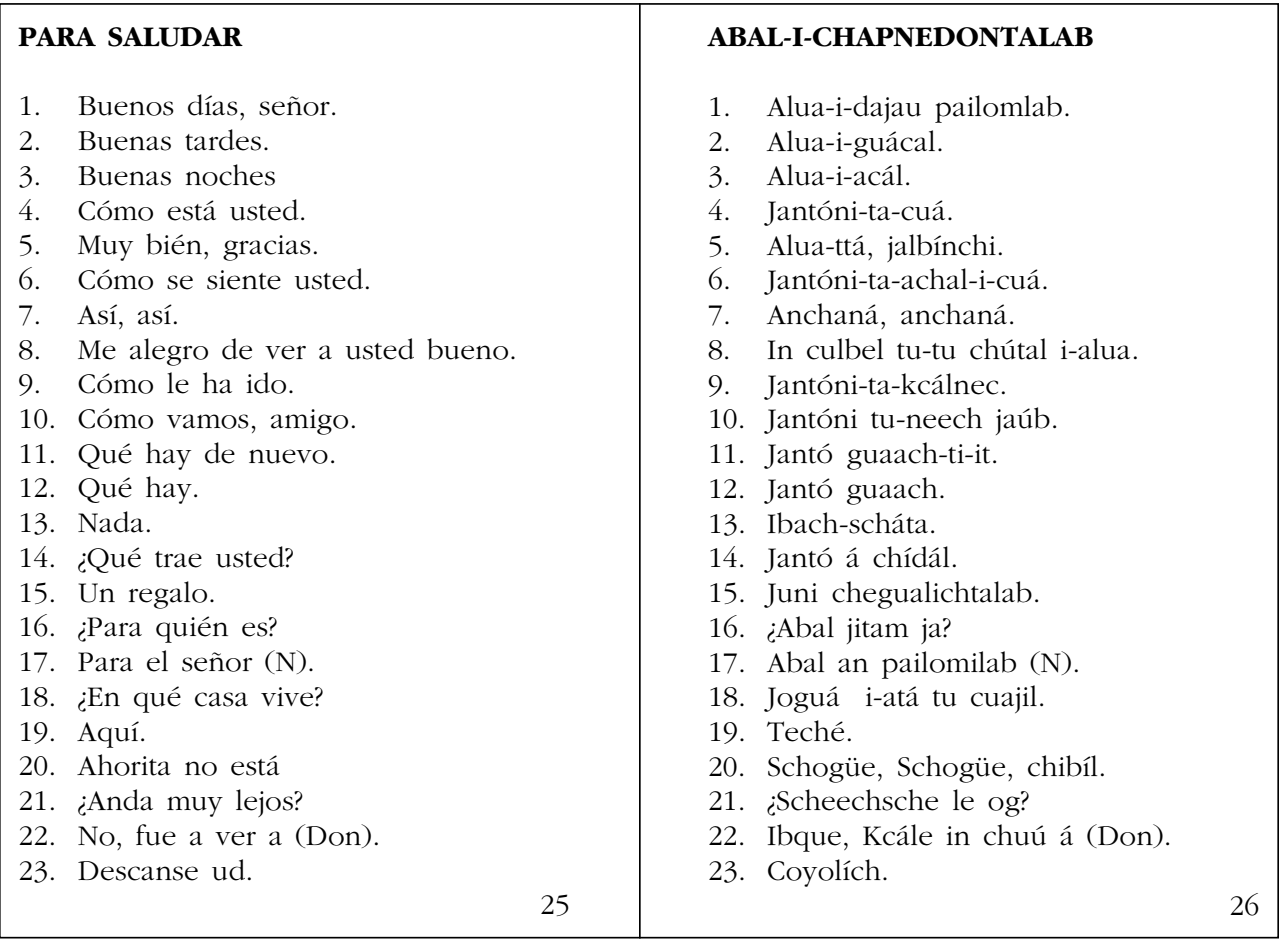

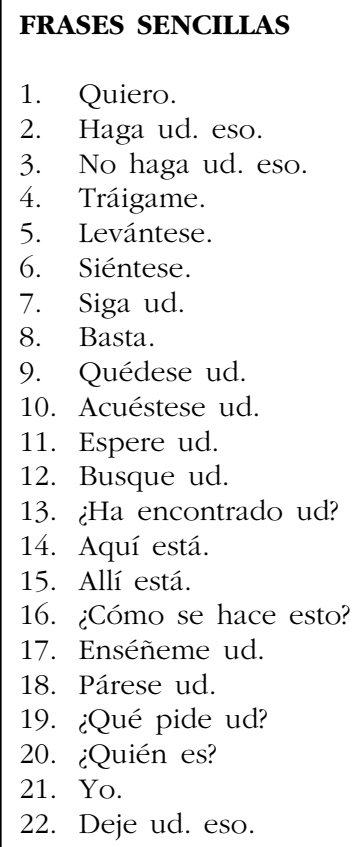

\section{CAUCHIC JUNCHIC}

1. U-lé.

2. Tajá-jachaná.

3. Ib cá lajá jachaná.

4. Ti quin chidánchill.

5. Chakcáll.

6. Cuajáll.

7. Honchíchtá.

8. Lejátqui.

9. Jilconích-tá.

10. Cuachích-tá.

11. Haichiy-tá.

12. Alíll-tá.

13. A-clámal-tá.

14. Jé-cuá.

15. Jachan cuá.

16. Jantóni tu táinal jeché?

17. Occhill-nálle.

18. Cubéch-tá.

19. Jantó á cónial.

20. Jitám játi.

21. Naná.

22. Jiláich-tá jachán. 


\begin{tabular}{|l|l|}
\hline 1. Tire ud. eso. & 1. Cüína jachán. \\
2. Salga ud. & 2. Cáley ó caléch-tá. \\
3. Entre ud. & 3. Ochichich-tá. \\
4. Con el permiso de ud. & 4. Cal tatá á agüiltal. \\
5. ¿Me da ud. licencia? & 5. Tin pidal ti licencia? \\
6. ¿Oye ud.? & 6. Achálsche? \\
7. Llame ud. & 7. Caníll-tá. \\
8. Pregunte ud. & 8. Conoll-tá. \\
9. Vaya ud. & 9. Kcaléch-tá. \\
10. No oigo. & 10. Llába ú-achál. \\
11. ¿Quiere ud. venir? & 11. Léta quí chich. \\
12. No hable ud tanto. & 12. Ib qui lé cágüintá. \\
13. Hable ud. alto. & 13. Cagǘntá tekcát. \\
14. Más alto. & 14. Más tekcát. \\
15. No entiendo. & 15. Llába ú-eschbáyal. \\
16. No oigo. & 16. Llába ú achál. \\
17. No quiero ir. & 17. Llába ú-lé tin kcálel. \\
18. No veo. & 18. Llába ú-chútal. \\
19. Vaya ud. & 19. Güiniích-tá. \\
20. Tengo frío. & 20. Cool i-chállil. \\
21. Me voy. & 21. Nechich-ná. \\
22. Vámonos. & 22. Guanajich. \\
23. Es una equivocación. & 23. Jaich jun-i ojdeltalab. \\
24. Está ud. engañado. & 24. Tatá-i-cambinénec. \\
25. Estoy ocupado. & 25. Cuájat in tólid. \\
26. No tengo nada qué hacer. & 26. Llába ú-cool schatá-cu-tóna. \\
27. Tengo mucho qué hacer. & 27. Cool llán chatá cu tójna. \\
28. Vamos á ver. & 28. Guana qui chuú. \\
29. Tengo calor. & 29. Cool in kcáquil. \\
& \\
\hline
\end{tabular}

\begin{tabular}{|l|l|}
\hline 1. Voy á dormir. & 1. Neech tin guáyal. \\
2. Tengo hambre. & 2. In kcaílich. \\
3. Tengo sed. & 3. In chiquél. \\
4. Quiero agua. & 4. U-lé i-já. \\
5. Tengo miedo. & 5. In jiquél. \\
6. Tengo razón. & 6. Ú-coo i-chubaschtalab. \\
7. ¿Cuándo es? & 7. Joiquí-ti. \\
8. Hoy es. & 8. Schogüeich. \\
9. Es para ud. & 9. Jaích abal tatá. \\
10. Está en la calle. & 10. Cuájat ti calle. \\
11. Están fuera. & 12. Cuajáchic eleb. \\
12. Está de prisa. & 13. Cuájat cali jicatalab. \\
13. Estoy triste. & 14. Cuájat in culug. \\
14. Estoy alegre. & 15. Cuájat itíschbe. \\
15. Está enfadado. & 16. Cuajáchic cánat. \\
16. Están contentos. & 17. Cuájat tin dúchum. \\
17. Estoy escribiendo. & 18. Cuájat ti ajum. \\
18. Está leyendo. & 19. Cuajáchic ti aichisch. \\
19. Están esperando. & 20. U-lé quin cále. \\
20. Quiero salir. & 21. I-cáu ti ténec. \\
21. ¿Habla ud. huaxteco? & \\
\hline
\end{tabular}




\begin{tabular}{|l|l|}
\hline 22. ¿Habla ud. mexicano? & 22. I-cáu ti dacchám. \\
23. ¿Sabe hablar el castellano? & 23. A-güitál ta lab cáu. \\
24. Sí, señor. & 24. Ojní, pailomláb. \\
25. No, señor. & 25. Ibque, pailomláb. \\
26. ¿Va ud. á pasearse? & 26. ¿Neech ta tónel-tá? \\
27. ¿Para dónde va este camino? & 27. Abal jónti neech jeché i-bel. \\
28. Este camino va á México. & 28. Jeché-i-bel neech México. \\
29. Este camino va á Tantoyuca. & 29. Jeché-i-bel neech Tantoyuca. \\
\hline
\end{tabular}

\begin{tabular}{|l|ll|}
\hline 1. ¿Cuál es el camino que va para Huejutla? & 1. Joguáti an bel neech abál Dac-tocóll. \\
2. ¿Qué dice ud? & $\begin{array}{l}\text { 2. Jantó á ulal. } \\
\text { 3. No digo nada. }\end{array}$ \\
4. Tome ud. la copa de Jeréz. & $\begin{array}{l}\text { 3. Llaba schatá ú-úlal. } \\
\text { 5. No la tomaré. }\end{array}$ \\
\hline
\end{tabular}

\section{DINERO}

1. Un centavo.

2. Cuartilla.

3. Cinco centavos.

4. Un quinto.

5. Medio.

6. Diez centavos.

7. Un décimo.

8. Un real.

9. Veinticinco centavos.

10. Dos reales.

11. Una peseta.

12. Cincuenta centavos.

13. Cuatro reales.

14. Un tostón.

15. Seis reales.

16. Un peso.

17. Diez reales.

18. Doce reales.

19. Dos pesos.

20. Diez y ocho reales.

21. Veinte reales.

\section{TUMIN}

1. Jun centavo.

2. Cuartilla.

3. Vo-i-centavo.

4. Jun-i-quinto.

5. Melo.

6. Lájo i centavo.

7. Jun i-décimo.

8. Jun tumín.

9. Jun inic-vo-i-centavo.

10. Chab tumín.

11. Jun-i-peseta.

12. Chab inic laju-i-centavo.

13. Che tumín.

14. Jun-i-tostón.

15. Acac tumín.

16. Jun peso.

17. Láju tumín.

18. Jun peso ché.

19. Chab peso.

20. Láju guaschíc tumín.

21. Jun inic tumín.

\begin{tabular}{|l|l|}
\hline 22. Dos pesos cuatro reales. & 22. Chab peso ché. \\
23. Cinco pesos. & 23. Vo peso. \\
24. Siete pesos. & 24. Buc peso. \\
25. Veinte pesos. & 25. Jun inic peso. \\
26. Una onza de oro. & 26. Jun i onza i oro. \\
27. Cien pesos. & 27. Jun vo inic peso. \\
28. Mil pesos. & 28. Jun schí i peso. \\
\hline
\end{tabular}




\section{PARA COMPRAR Y VENDER}

1. Pasa, marchante.

2. Aquí hay todo lo que ud. quiera.

3. Hay ropa, papel, tabaco, aguardiente, etc.

4. ¿A cómo dá ud. la vara de manta?

5. A real; á real y cuartilla.

6. ¿Cuántas varas quiere?

7. Una, dos, cuatro, etc.

8. ¿A cómo da la vara de zaraza?

9. A real y cuartilla; á real y medio.

10. ¿A cómo dá el corte de dril?

11. A dos pesos dos reales.

12. ¿No quiere dar á catorce reales?

13. No, amigo.

14. Pierdo; yo he comprado á dos pesos.

15. Aquí hay también de á catorce.

16. ¿Qué trae, amigo?

17. Lazos, morrales, reatas y sombreros.

18. ¿A cómo dá la docena de lazos?

19. A cinco reales; á seis reales y medio.

\section{ABAL-I-CHAIMACH I NUJLACH'}

1. Guatell chaúm.

2. Teché guaach schatá an ca légna.

3. Guaach i-cúdcum, ug, mall, voc, etc.

4. Játua ta pidnal an vara an manta.

5. Ti jun tumín. Ti jun tumín y cuartilla.

6. Jall i vara á lé.

7. Jun, chab, ché, etc.

8. Játua ta pidnal an vara an sarasa.

9. Ti jun tumín i cuartilla. Tin jun tuy-melo.

10. Játua ta pidnal an corte and dril.

11. Ti chab peso chab tumín.

12. Llaba á lé ca pidá cal láju ché tumín.

13. Ibque, jaub.

14. In quíbel, naná ú chayámal ti chab peso.

15. Je guaach jálle ti laju che tumín.

16. ¿Jantó á chidal jaub?

17. Ládju, morral, reata y sumbrerochic.

18. Játua ta pidnal an docena an ládju.

19. Ti vo tumín; ti acac tuy melo.
20. ¿A cómo paga ud?

21. A tres y medio.

22. ¿Cuánto vale un lacito?

23. Cinco centavos.

24. Cómpralo para que amarre zacate.

25. Cómprame un morral.

26. ¿Cuánto vale?

27. Un real.

28. ¿Quiere medio y cuartilla?

29. No, en once centavos se lo doy.

30. ¿Cuánto vale una docena?

31. Doce reales, diez reales.

32. ¿Cuánto vale la lazadera?

33. Dos y medio.

34. ¿Cuánto vale un sombrero?

35. Cuatro reales.

36. Cómpralo; está muy bonito.

37. Aquí hay chicos para los niños.

\section{NÚMEROS}

1. Uno, dos tres, cuatro.

2. Cinco, seis, siete.

3. Ocho, nueve, diez.

4. Once, doce.

5. Trece, catorce.

6. Quince, diez y seis.

7. Diez y siete, diez y ocho.

8. Diez y nueve, veinte.
20. Játua ta jalbillál-tá.

21. Ti osch tuy melo.

22. Játua in jalbil jun lájdu.

23. Vo i centavo.

24. Ca chaach abal cá güicá i scheqlec.

25. Ti quin chaichich jun i moral.

26. ¿Játua in jalbíl?

27. Jun tumín.

28. A lé melo y cuartilla.

29. Cal laju jun i centavo tu tu pídal.

30. Játua in jalbil jun i docena.

31. Jun peso che; láju tumín.

32. Játua in jalbíl an chajuschtalab.

33. Chab tuy melo.

34. Játua in jalbil jun i sumbrero.

35. Che tumín.

36. Ca chaach alabel táj.

37. Je guaach chichiq abal i chacamchiq.

\section{NUMEROCHIC}

1. Jún, chab, osch, che.

2. Vo, acac, buc.

3. Guaschíc, beleju, láju.

4. Láju jún, láju-chab.

5. Láju-osch, láju-ché.

6. Láju-vo, láju-acac.

7. Láju-buc, láju-guaschíc.

8. Láju-beleju, jun-inic. 


\begin{tabular}{|c|c|c|}
\hline $\begin{array}{l}\text { 1. Veintiuno. } \\
\text { 2. Veintidos. } \\
\text { 3. Veintitres. } \\
\text { 4. Veinticuatro. } \\
\text { 5. Veinticinco. } \\
\text { 6. Veintiseis. } \\
\text { 7. Veintisiete. } \\
\text { 8. Veintiocho. } \\
\text { 9. Veintinueve. } \\
\text { 10. Treinta. } \\
\text { 11. Treinta y uno. } \\
\text { 12. Treinta y dos. } \\
\text { 13. Cuarenta. } \\
\text { 14. Cuarenta y uno. } \\
\text { 15. Cincuenta. } \\
\text { 16. Cincuenta y uno. } \\
\text { 17. Cincuenta y dos. } \\
\text { 18. Sesenta. } \\
\text { 19. Sesenta y uno. } \\
\text { 20. Sesenta y dos. } \\
\text { 21. Setenta. } \\
\text { 22. Setenta y uno. } \\
\text { 23. Ochenta. } \\
\text { 24. Ochenta y uno. } \\
\text { 25. Noventa. } \\
\text { 26. Noventa y uno. } \\
\text { 27. Cien. } \\
\text { 28. Ciento uno. } \\
\text { 29. Ciento diez. } \\
\end{array}$ & 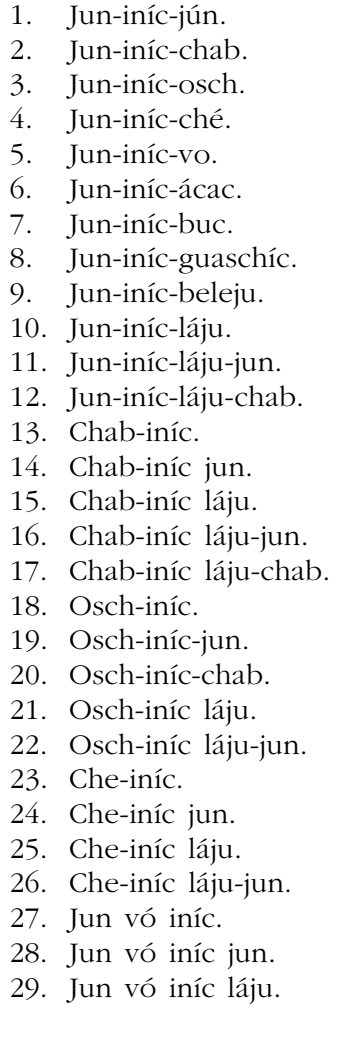 & 40 \\
\hline
\end{tabular}

30. Ciento veinte.

31. Doscientos.

32. Trescientos.

33. Cuatrocientos.

34. Quinientos.

35. Un mil.

36. Dos mil.

37. Veinte mil.

38. Cien mil.

\section{PARA PREGUNTARLE A UN AMIGO}

1. ¿Qué hay amigo?

2. ¿A dónde va?

3. Voy á mi casa.

4. ¿De dónde viene?

5. Vengo del pueblo.

6. Vengo de la milpa.

7. ¿Qué lleva?

8. ¿Dónde vive?
30. Acac iníc.

31. Chab vó iníc.

32. Osch vó iníc.

33. Che vó iníc.

34. Vó vó iníc.

35. Jun schí.

36. Chab schí.

37. Jun iníc schí.

38. Jun vó iníc schí.

\section{ABAL QUI CONOLL JUN I JAUB}

1. Jantó guaach jaub.

2. Jónta neech.

3. In neech tu quimá.

4. ¿Jóni ta tál?

5. In tál ti albichón.

6. In tál ti alelab.

7. ¿Jantó á nejdal?

8. ¿Jónta cuajil? 


\begin{tabular}{|l|l|}
\hline 9. Yo vivo lejos. & 9. Naná in cuajil ogüel. \\
10. ¿Y ud.? & 10. An tatá ti. \\
11. Yo, allí, en la loma. & 11. Naná, jachan óquin bólchal. \\
12. ¿Cómo se llama ud? & 12. ¿Jantóni á bí tá? \\
13. Pedro, Juan, etc. & 13. Pedro, Juan, etc. \\
14. ¿Tiene ud. hermanos? & 14. ¿A cool á quiddabchic? \\
15. Tengo dos. & 15. U cool chab. \\
16. ¿No los conoce? & 16. ¿Llaba á eschlalchiq? \\
17. Buen caballo lleva ud. & 17. Aluá bichín á junal. \\
\hline
\end{tabular}

18. ¿Cuánto le costó?

19. Cuarenta pesos.

20. ¿Qué, es nuevo?

21. No, es viejo.

22. ¿No lo quiere vender?

23. Le vendo una yegua grande.

24. ¿Dónde la tiene?

25. La tengo en el potrero.

26. Tiene un potrito.

27. Dame dos toretes por ella.

28. ¿Quién tiene aquí un burro?

29. Aquí ninguno.

30. ¿Quién tiene aquí marranos gordos?

31. Allí en la otra casa tienen.

32. ¿No vende ud. esos pollitos?

33. Sí, los vendo.

34. Le vendo un venado.

35. ¿No tiene ud. cueros de res?

36. ¿A cómo dá la libra?

37. ¿A cómo la paga ud?

\section{EN UNA SASTRERIA}

1. Necesito un traje completo.

2. ¿Cuándo vengo para medírmelo?

3. Quiero un pantalón.

4. Quiero un saco.

5. Quiero una camisa.

6. ¿Cuánto valen los calzoncillos?
18. Játua ta chaáy.

19. Chab iníc peso.

20. ¿Itsché?

21. Ibque, llechélich.

22. Llaba á lé ca nujúg.

23. Tu tu núchal jun i yegua púlec.

24. ¿Jóni ta cool?

25. U cool al potrero.

26. In cool jun i chácam potro.

27. Pída chal i toro cal.

28. Jita in cool teché jun i burro.

29. Teché ni junschíta.

30. Jitám já, in cool teché i ólom cochdá.

31. Jachán jun atá ú coyáb.

32. ¿Llaba á nujgual jachan i póllochiq?

33. Ojní ú nújgual.

34. Jútu nújchal jun i ichámal.

35. ¿Llaba á cool in otól i pacasch?

36. ¿Játua ta pídnal an libra?

37. ¿Jatuá ta jalbillal tá?

\section{AL JUN I SASTRERIA}

1. U llénchal jun ú cuajbaschtal ócod.

2. jJoiqui quin chich abal cu léjball?

3. U lé jun u-pantalón.

4. U lé jun u saco.

5. U lé jun u schequét.

6. jJátua in jalbil an patebláb?
7. Me gusta este paño.

8. ¿Cuánto cuesta este género?

9. Necesito esto para el domingo.

10. Es muy caro.

\section{EN UNA TABAQUERIA}

1. Quiero algunos puros.

2. Quiero mejor tabaco.

3. ¿Cuánto cuesta una caja de cigarros?
7. U culbetnal jeché i paño.

8. ¿Játua in jalbil jeche i género?

9. U llénchal jeché abal domingo.

10. Cájbid tá.

\section{AL JUN I MAILOM}

1. U lé i púroschic.

2. U lé i mai aluá.

3. ¿Játua in jalbil jun i-caja i-cigarro? 


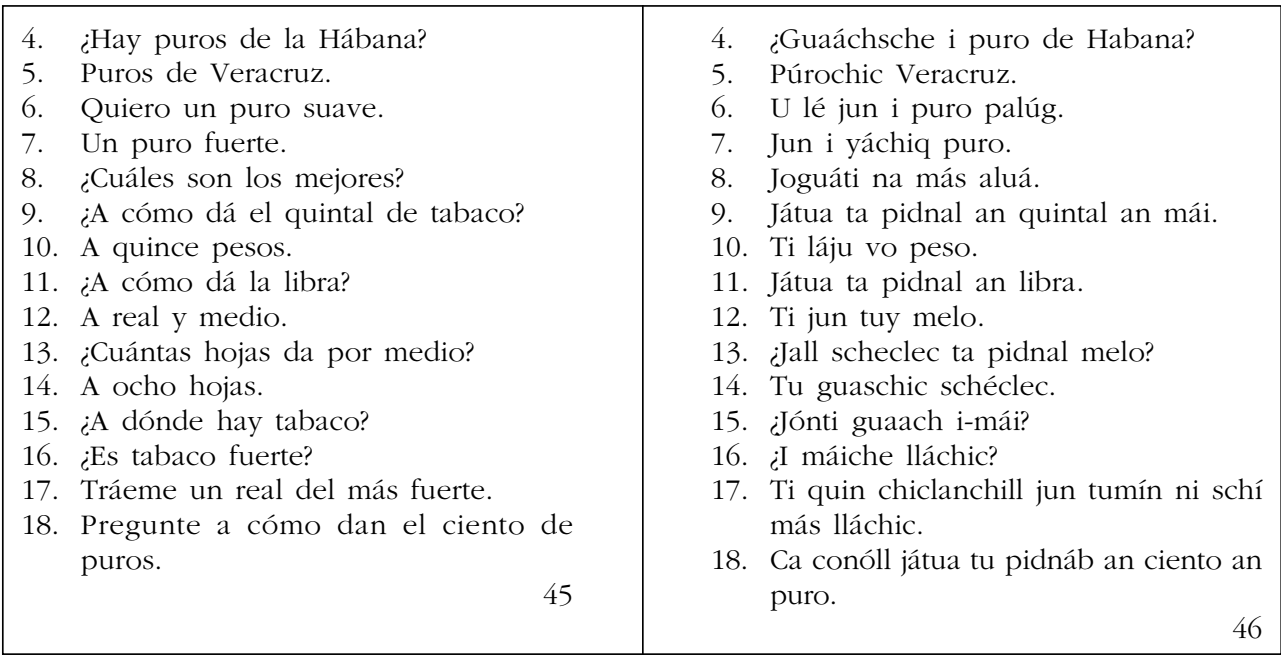

\section{PREGUNTAS QUE LE HAGAN A UN DES- CONOCIDO}

1. ¿Cómo se llama ud?

2. ¿De dónde viene ud?

3. Vengo de Puebla.

4. ¿Qué trae?

5. ¿Qué oficio tiene?

6. ¿En qué se ocupa ud?

7. ¿Dónde vive?

8. ¿De dónde es ud?

9. Yo soy de Hidalgo.

10. ¿Paga ud. las contribuciones?

11. Sí señor, las pago.

12. ¿Dónde están los recibos?

13. ¿Qué tiempo tiene de estar aquí?

14. Tengo un mes.

15. Catorce días.

16. Mis recibos los dejé en San Vicente.

17. Es mentira.

18. ¿No me engaña ud?

19. Usted es muy embustero.

20. ¿Cuándo llegó aquí?

21. Ayer en la tarde.

22. ¿Con quién vino ud?

23. ¿Cómo se llama su compañero?

24. Yo me vine el viérnes.

25. Yo solo.

\section{CONOSCHTALAB CA TACHIN JUN LLABA ESCHLAGUALE}

1. Jantóni á bí tá.

2. Jóni ta tal ta.

3. In tal ti Puebla.

4. Jantó á chídal.

5. jJantóm oficio á cool?

6. Jantólá tólinal tá.

7. Jónta cuajil.

8. Jónti tá inic tá.

9. Naná ti Hidalgo.

10. A jalbillal an contribucionchic.

11. Ojni, pailomlab ú jalbillálchic.

12. ¿Jóni ti cuá an recibochic?

13. Jantóm qui á cool ta cuá teché.

14. U cool jun á ich.

15. Láju-ché á quichá.

16. Nu recibojílchic ú jilá ti San-Vicente.

17. I-cambísch.

18. ¿Ibach tin cambillal?

19. Tátá lé i-cámbisch.

20. Joiqui ta ulich teché.

21. Güeel guácal.

22. Cal jitá tá chích.

23. Jíta in bí na juníctá.

24. Naná, in chích ti viérnes.

25. Naná cuetém. 


\begin{tabular}{|c|c|}
\hline 26. :Oué trajo su compañero? & 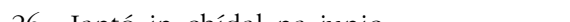 \\
\hline 27. ¿Conoce ud. á Don $(\mathrm{N})$. & 27. A eschlálsche na $(\mathrm{N})$. \\
\hline 28. Ese señor que está allí ¿lo conoce ud? & 28. ¿Jachan i-pailomlab cuá á eschlálsche? \\
\hline 29. Sí señor, lo conozco. & 29. Ojni pailomlab ú eschlal. \\
\hline 30. No lo conozco. & 30. Ibque ú eschlál. \\
\hline 31. ¿Cómo se llama ese hombre? & 31. ¿Jantóni in bi jachán i iníc? \\
\hline 32. No sé. & 32. Ibque ú choób. \\
\hline 33. ¿Dónde lo ha visto? & 33. ¿Jóni ta chuúmal? \\
\hline 34. En su casa. & 34. Tin quimá. \\
\hline 35. ¿Dónde tiene la casa? & 35. jóni tin coól ni quimá? \\
\hline 36. En un rancho llamado San Agustín. & 36. Al jun i rancho bijid ti San Agustín. \\
\hline 37. ¿Qué tiene en ese rancho? & 37. ¿Jantó in cool al jachán i rancho? \\
\hline 38. No tiene nada. & 38. Ibach scháta in coól. \\
\hline NOMBRES DE ANIMALES CUADRUPEDOS & BI I-ANIMALCHIC CHE ACAN \\
\hline 1. Caballo. & 1. Bichím. \\
\hline 2. Potro. & 2. Potro. \\
\hline 3. Caballito. & 3. Chacám bichím. \\
\hline 4. Yegua. & 4. Yegua. \\
\hline 5. Potranca. & 5. Potranca. \\
\hline 6. Macho. & 6. Macho. \\
\hline 7. Mula. & 7. Mula. \\
\hline 8. Burro. & Burro. \\
\hline 9. Burra. & 9. Burra. \\
\hline 10. Toro. & 10. Toro. \\
\hline 11. Vaca. & 11. Pácasch. \\
\hline $\begin{array}{l}\text { 12. Becerro, ternera. (El toro, la vaca, el } \\
\text { becerro y la ternera juntos se llaman } \\
\text { pácaschchíc). }\end{array}$ & 12. Becérru, ternera. \\
\hline 49 & 50 \\
\hline
\end{tabular}

\begin{tabular}{|l|l}
\hline 13. Perro y perra. & 13. Picó. \\
14. Perra. & 14. Uschúm picó. \\
15. Perrito. & 15. Chacám picó. \\
16. Gato y gata. & 16. Mischtú. \\
17. Gato. & 17. Iinic mischtú. \\
18. Gata. & 18. Uschum mischtú. \\
19. Conejo y coneja. & 19. Cóy. \\
20. Borrego, borrega. & 21. Borrego, borrega. \\
21. Chivo. & 22. Uschum chivo. \\
22. Cabra. & 23. Ichámal. \\
23. Venado y venada. & 24. Olóm. \\
24. Puerco y puerca. & 25. Tióm. \\
25. Gamito. & 26. Alté olóm. \\
26. Jabalí. & 27. Chác-núc ó ráu. \\
27. (La) Zorra. & 28. Edém. \\
28. Mapache. & 29. Utt. \\
29. Zorrillo y Tlacuache. & 30. Batau ó pitin. \\
30. Armadillo. & 31. Besché. \\
31. Tejón. & 32. Tucúm. \\
32. Ardilla. &
\end{tabular}




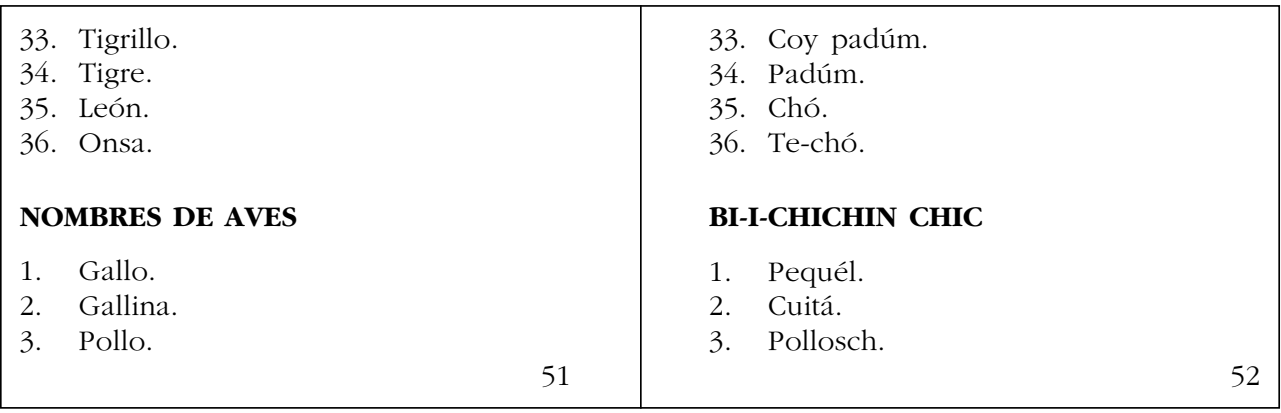

$\begin{array}{ll}\text { 4. } & \text { Guajolote. } \\ \text { 5. } & \text { Paloma. Perdíz. } \\ \text { 6. } & \text { Codorniz. } \\ \text { 7. } & \text { Zopilote. Gavilán. } \\ \text { 8. } & \text { Tordo. Garza. } \\ \text { 9. } & \text { Gallina de agua. } \\ \text { 10. } & \text { Lechuza. } \\ \text { 11. } & \text { Buho. Pusuáca. } \\ \text { 12. } & \text { Loro. Cotorra. }\end{array}$

\section{NOMBRES DE OTROS ANIMALES}

1. Culebra. Lagartija.

2. Lagarto. Iguana.

3. Víbora. Sapo. Rana.

4. Tortuga. Galápago.

5. Alacrán. Araña.

6. Tarántula.

7. Cucaracha. Mosca.

8. Enjambre. Gusano.

9. Mariposa. Hormiga.

10. Arriera. Tepehua.

11. Pulga. Garrapata.

12. Conchuda. Piojo.

13. Liendre.

\section{NOMBRES DE COSAS}

1. Piedra. Palo. Hierro.

2. Lumbre. Leña.

3. Agua. Pilón.
4. Guájolote ó cadáu.

5. Cucú. Güéguoy.

6. Cubí.

7. Tót. Tihu.

8. Chóc. Jó.

9. Aljá cuitá.

10. Cúschcúm.

11. Jujúm. Güillóm.

12. Loro. Cuchú.

\section{BI QUEET-I-CONELCHIC}

1. Chan. Ochó.

2. Ajín. Odóg.

3. Dotót. Cuá. Hó.

4. Pét. (Los dos se llaman así).

5. Dinill. Am.

6. Cuadáb.

7. Colól. Janéc.

8. Sapshám. Dúm.

9. Lóm. Daních.

10. Tidid. Lác.

11. Chác. Tip.

12. Schechém. Uch.

13. Taám.

\section{BICHIC-I-HEILAB}

1. Tujúb. Té. Patál.

2. Camál. Dí.

3. Já. Tinóm.

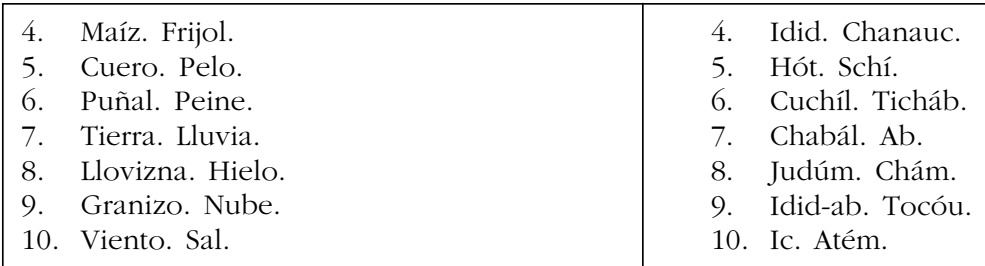




\begin{tabular}{|l|l|}
\hline 11. Chapopote. Arena. & 11. Cápet. Quidíb. \\
12. Brea. Pedernal. & 12. Güidab. Táj. \\
13. Espejo. Aguja. & 13. Lám. Tidám. \\
NOMBRES DE PARENTESCO & BICHIC-I-JAUBLOMTALAB \\
1. Padre. Madre. Hijo. & 1. Tata. Nána. Chacámil. \\
2. Hermano y hermana. & 2. Quidáb. \\
3. Tío. Tía. & 3. Pailóm. Mím. \\
4. Padrino. Madrina. & 4. Lab-pailóm. La-mim. \\
5. Abuelo. Abuela. & 5. Mam. Ach. \\
6. Bisabuelo. Bisabuela. & 7. Chabil-mam. Chabil-ach. \\
7. Sobrino y sobrina. & 8. Ball. Atmúl. \\
8. Cuñado. Cuñada. & 9. Illám. Alhib. \\
9. Yerno. Nuera. & 10. Hachí. \\
10. Consuegro y consuegra. & 11. Momób. \\
11. Nieto y nieta. & 12. Lab-cuitólil. \\
12. Ahijado. & 14. Inic illám. Uschúm illám. \\
13. Ahijada. & \\
14. Suegro. Suegra. & \\
\hline
\end{tabular}

\section{NOMBRES DE LAS PARTES DEL} CUERPO HUMANO

1. Cabeza. Cabello.

2. Frente. Cejas.

3. Ojos. Pestaña.

4. Orejas. Nariz.

5. Párpados. Boca.

6. Labios.

7. Labio superior.

8. Labio inferior.

9. Dientes. Lengua.

10. Paladar. Garganta.

11. Quijada. Sien.

12. Barba. Nuca.

13. Brazos. Manos.

14. Brazo derecho.

15. Brazo izquierdo.

16. Codo. Corazón.

17. Costillas. Estómago.

18. Piernas. Rodilla.

19. Piés. Talón.

20. Uña. Espinazo. Cadera.

21. Vena. Hueso. Piel.

Los meses del año se dicen igualmente en huaxteco como en castellano.

Los días de la semana también.

\section{BILAB QUECHIC IN TUUL AN INICTALAB}

1. Oc. Schiíl.

2. Píquib, Maschúsch.

3. Gual. Schiíl y gual.

4. Schuchun, Dám.

5. Otol-i-gual. Güi.

6. Otol-i-güi.

7. Ebal otol-i-güi.

8. Alal otol-i-güi.

9. Camáb. Lecáb.

10. Tacám. Cutúmtal.

11. Cháub. Dadál.

12. Ischím. Nuc.

13. Ocób. Cubác.

14. Ejat ocób.

15. Cuatab ocób.

16. Tillic. Ichich.

17. Chollil. Chucúl.

18. Chejét. Cualal.

19. Acán. Chijím.

20. Ichic. Cúsch. Cuecuén.

21. Anúch. Becléc. Otól.

In ichálchic an tamúb, ú uluáb jelattéqui an ti ténec jantóni an ti labcáu.

In quichájilchic an semana jállequi. 


\begin{tabular}{|c|c|c|c|}
\hline I N D I C E & \multirow[b]{2}{*}{ Págs. } & \multicolumn{2}{|l|}{ OLNASCHTALAB } \\
\hline & & & Págs. \\
\hline 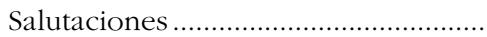 & 25 & 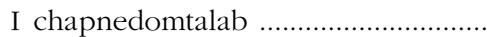 & 26 \\
\hline Frases sencillas & 27 & Cáuchic Júnchic & 28 \\
\hline Dinero & 33 & Tumín & 34 \\
\hline Compra y venta & 35 & 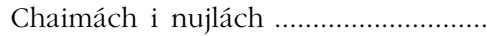 & 36 \\
\hline Números & 37 & Numerochic & 37 \\
\hline Para preguntarle á un amigo ............. & 41 & Abal qui conoll jun i jaub .... & 42 \\
\hline 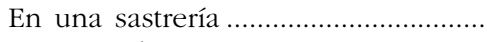 & 43 & 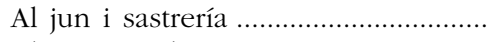 & 44 \\
\hline En una tabaquería .................................. & 45 & Al jun i máilom & 46 \\
\hline $\begin{array}{l}\text { Preguntas que le hagan a un desco- } \\
\text { nocido }\end{array}$ & 47 & $\begin{array}{l}\text { Conohuischtalab ca táchin jun llaba } \\
\text { eschlaguale }\end{array}$ & 48 \\
\hline Nombres de animales cuadrúpedos .. & 49 & 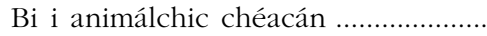 & 50 \\
\hline 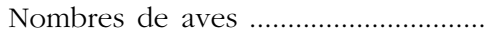 & 51 & Bi i chichinchic & 52 \\
\hline Nombres de otros animales ............... & 53 & 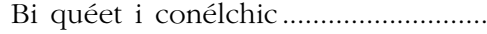 & 54 \\
\hline 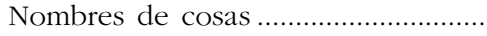 & 53 & Bíchic i heilab............ & 54 \\
\hline Nombres de parentesco ...................... & 55 & 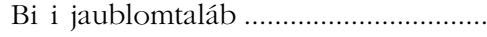 & 56 \\
\hline $\begin{array}{l}\text { Nombres de las partes del cuerpo } \\
\text { humano }\end{array}$ & 58 & Bilab quéchic in tuúl an inichtalab . & 58 \\
\hline
\end{tabular}

\section{BIBLIOGRAFÍA CITADA}

Alcorn, J. 1984. Huastec Mayan Ethnobotany. Norman: University of Oklahoma Press.

Ariel de Vidas, A. 2003. El trueno ya no vive aquí. Representación de la marginalidad y construcción de la identidad teenek (Huasteca veracruzana, México). México: CIESAS/COLSAN/CEMCA/ IRD.

Del Ángel Flores, N. I. 2006. "Dhipaak: el culto al maíz entre los teenek de la Sierra de Otontepec". Universo 6, no. 224.

Gallardo Arias, P. 2004. Huastecos de San Luis Potosí. México: CDI.

Grosser Lerner, E. 1991. Los tének de San Luis Potosí: lengua y contexto. México: Instituto Nacional de Antropología e Historia.

Larsen, R. 1991. Vocabulario Huasteco del Estado de San Luis Potosí. México: ILV/SEP.

Martínez Hernández, R. 2002. Xantolo, el día de muertos en la Huasteca veracruzana. México: Propuesta Editorial.

Ochoa, Á. 1984. El idioma huasteco de Xiloxúchil, Veracruz. México: Instituto Nacional de Antropología e Historia.

Ochoa, Á. 2000. "Las aventuras de Dhipaak o dos facetas del sacrificio en la mitología de los teenek (huastecos)". Dimensión antropológica 20: 101-123.

Ruvalcaba Mercado, J. 1987. Vida cotidiana y consumo de maiz en la Huasteca veracruzana. México: CIESAS (Cuadernos de la Casa Chata 134).

Ruvalcaba Mercado, J. y Alcalá, G. (coords.). 1993. Huasteca. Selección de trabajos pertenecientes al $V y$ VI encuentros de investigadores de la Huasteca. (3t.) México: CIESAS.

Valle Esquivel, J. 2004. Nahuas de la Huasteca. México: CDI.

Valle Esquivel, J. y Hernández Alvarado, J. B. 2006. Huastecos de Veracruz. México: CDI. 